\title{
Parabacteroides gordonii sp. nov., isolated from human blood cultures
}

Correspondence
Mitsuo Sakamoto
sakamoto@jcm.riken.jp

\author{
Mitsuo Sakamoto, ${ }^{1}$ Natsuko Suzuki, ${ }^{1}$ Naohisa Matsunaga, ${ }^{2}$ \\ Kimihito Koshihara, ${ }^{2}$ Masayasu Seki, ${ }^{3}$ Hideaki Komiya ${ }^{3}$ \\ and Yoshimi Benno ${ }^{1}$
}
${ }^{1}$ Microbe Division/Japan Collection of Microorganisms, RIKEN BioResource Center, Wako, Saitama 351-0198, Japan
${ }^{2}$ Department of Infection Control and Prevention, Tokyo Medical University Hospital, Shinjuku-ku, Tokyo 160-0023, Japan
${ }^{3}$ Department of General Medical and Primary Care, Tokyo Medical University Hospital, Shinjuku-ku, Tokyo 160-0023, Japan

\begin{abstract}
Three bacterial strains that had been isolated from human blood cultures, MS-1 ${ }^{\top}, \mathrm{MS}-2$ and MS3, were characterized for their phenotypic and biochemical features, cellular fatty acid profiles, menaquinone profiles and phylogenetic positions based on 16S rRNA gene sequence analysis. 16S rRNA gene sequence analysis showed that the isolates were members of the genus Parabacteroides. These isolates were most closely related to Parabacteroides goldsteinii JCM $13446^{\top}$, with $95.9 \% 16 \mathrm{~S}$ rRNA gene sequence similarity. The levels of sequence similarity among the three strains were $99.7-100 \%$. The isolates were obligately anaerobic, nonpigmented, non-spore-forming, non-motile, Gram-negative and rod-shaped. The strains grew on media containing $20 \%$ bile. These strains could be differentiated from P. goldsteinii by their ability to ferment L-arabinose and inabilities to ferment cellobiose, L-rhamnose and trehalose or to hydrolyse aesculin. The major menaquinone of the isolates was MK-10. Based on these data, we propose a novel Parabacteroides species, Parabacteroides gordonii sp. nov. The type strain is MS-1 ${ }^{\top}\left(=\right.$ JCM $15724^{\top}=$ CCUG $\left.57478^{\top}\right)$.
\end{abstract}

The genus Parabacteroides was proposed by Sakamoto \& Benno (2006) for three 'outmembers' of the genus Bacteroides, Bacteroides distasonis (Eggerth \& Gagnon, 1933), B. goldsteinii (Song et al., 2005) and B. merdae (Johnson et al., 1986). Sakamoto et al. (2007) subsequently proposed a fourth species of the genus, Parabacteroides johnsonii. These species are phylogenetically distinct from species of the genus Bacteroides and are related to Tannerella forsythia (Sakamoto et al., 2002). Parabacteroides species are isolated mainly from human faeces and clinical specimens, such as peritoneal fluids, appendix tissues and intra-abdominal abscesses (Song et al., 2005). The present study was designed to determine the taxonomic status of three strains of Gram-negative, obligately anaerobic rods that had been isolated from human blood cultures.

Strains MS- $1^{\mathrm{T}}$, MS-2 and MS-3 were isolated from blood cultures (days 1, 6 and 9) from a 73-year-old Japanese male

Abbreviation: FAME, fatty acid methyl ester.

The GenBank/EMBL/DDBJ accession numbers for the 16S rRNA gene sequences of strains MS- $1^{\top}, M S-2$ and MS-3 are AB470343AB470345, respectively. presenting with a 1-week history of fever and diarrhoea. An abdominal computed tomography scan showed a large liver with central necrosis and hepatocellular carcinoma. Due to the patient's unstable status, a liver biopsy and treatment for the presumed carcinoma were deferred. Sputum, urine and stool cultures did not contain the same isolates. Strains MS- $1^{\mathrm{T}}$, MS-2 and MS-3 were maintained on Eggerth Gagnon (EG) agar (Merck) supplemented with $5 \%$ (v/v) horse blood for 2 days at $37{ }^{\circ} \mathrm{C}$ in an atmosphere containing $100 \% \mathrm{CO}_{2}$. For this study, Parabacteroides goldsteinii JCM $13446^{\mathrm{T}}$ was obtained and subjected to some of the phenotypic and biochemical tests.

Bacteroides bile aesculin agar (Shah, 1992) was used to check whether bile inhibited growth of the isolates. Physiological and biochemical reactions were determined in duplicate with the API $20 \mathrm{~A}$ anaerobe test kit and the Rapid ID 32A anaerobe identification kit, respectively (bioMérieux), according to the manufacturer's instructions. The metabolic end products were prepared as described by Holdeman et al. (1977) and were analysed as described previously by Sakamoto et al. (2005). Fatty acid methyl esters (FAMEs) were obtained from about 
$40 \mathrm{mg}$ wet cells by saponification, methylation and extraction using minor modifications (Kuykendall et al., 1988) of the method of Miller (1982). Cellular fatty acid profiles were determined with the Microbial Identification System (Microbial ID; MIDI). Isoprenoid quinones were extracted as described by Komagata \& Suzuki (1987) and were analysed as described previously by Sakamoto et al. (2002).

Chromosomal DNA was isolated using described methods (Marmur, 1961; Saito \& Miura, 1963) with some modifications. The DNA base composition was determined with the HPLC method of Tamaoka \& Komagata (1984). The elution solvent was a mixture of $0.02 \mathrm{M} \mathrm{NH}_{4} \mathrm{H}_{2} \mathrm{PO}_{4}$ and acetonitrile $(20: 1, \mathrm{v} / \mathrm{v})$. The $16 \mathrm{~S}$ rRNA gene sequence was analysed as described previously (Sakamoto et al., 2002). Related sequences were aligned with the CLUSTAL $X$ version 2.0 program (Larkin et al., 2007) and the alignment was corrected manually. After gaps and unknown bases were eliminated, nucleotide substitution rates ( $K_{\text {nuc }}$ values) were calculated (Kimura, 1980). The phylogenetic tree was constructed with the neighbour-joining method (Saitou \& Nei, 1987). A bootstrap resampling analysis (Felsenstein, 1985) was performed to evaluate the confidence limits of tree topologies.

Cells of strains MS- ${ }^{\mathrm{T}}$, MS-2 and MS-3 were nonpigmented, non-spore-forming and non-motile. The growth of the isolates was not inhibited on medium containing $20 \%$ bile. Cells on EG agar were $0.8 \mu \mathrm{m}$ by $1.7-$ $2.5 \mu \mathrm{m}$ in size and occurred singly. Colonies on EG agar after $48 \mathrm{~h}$ of incubation at $37{ }^{\circ} \mathrm{C}$ under anaerobic conditions were $1-2 \mathrm{~mm}$ in diameter, grey to off-whitegrey, circular, entire, slightly convex and smooth. Phenotypic characteristics are given in the species description and in Table 1. These strains could be differentiated from Parabacteroides goldsteinii JCM $13446^{\mathrm{T}}$ by their ability to ferment $\mathrm{L}$-arabinose and inability to ferment cellobiose, L-rhamnose and trehalose or to hydrolyse aesculin with the API 20A kit. Catalase activity was not detected with the API $20 \mathrm{~A}$ kit but it was detected on EG agar. Using the Rapid ID $32 \mathrm{~A}$ kit, these strains could be differentiated from $P$. goldsteinii JCM $13446^{\mathrm{T}}$ by the presence of $\alpha$-arabinosidase activity and the lack of $\beta$-glucosidase, phenylalanine arylamidase, tyrosine arylamidase, glycine arylamidase, histidine arylamidase, glutamyl glutamic acid arylamidase and serine arylamidase activities.

The major cellular fatty acid of the isolates was anteiso15: $0(42-47 \%)$ (Table 2). The proportion of anteiso-15:0 was larger than those recorded for other Parabacteroides species (25-32\%), while the proportion of iso-17:0 $3-\mathrm{OH}$ $(2-5 \%)$ was significantly smaller than for other Parabacteroides species (21-26\%) (Sakamoto \& Benno, 2006; Sakamoto et al., 2007). The major menaquinones of two isolates (MS- $1^{\mathrm{T}}$ and MS-2) were MK-9 (10 and $\left.9 \%\right)$, MK-10 (72 and $71 \%$ ) and MK-11 (13 and 14\%), respectively. Minor amounts of MK-8 (1 and 2\%) were also present. The menaquinone compositions of the
Table 1. Differential characteristics of Parabacteroides gordonii sp. nov. and other Parabacteroides species

Taxa: 1, Parabacteroides gordonii sp. nov. $(n=3) ; 2$, P. goldsteinii JCM $13446^{\mathrm{T}}$ (data from this study and Song et al., 2005); 3, P. distasonis; 4, P. johnsonii; 5, P. merdae [data in columns 3-5 from Sakamoto \& Benno (2006) and Sakamoto et al. (2007)]. +, Positive; w, weakly positive; $v$, variable; - , negative.

\begin{tabular}{|c|c|c|c|c|c|}
\hline Characteristic & 1 & 2 & 3 & 4 & 5 \\
\hline Catalase production & $\mathrm{V}$ & $\mathrm{V}$ & + & + & - \\
\hline Aesculin hydrolysis & - & + & + & + & + \\
\hline \multicolumn{6}{|l|}{ Acid produced from: } \\
\hline Salicin & - & - & + & - & - \\
\hline L-Arabinose & + & - & - & + & - \\
\hline Cellobiose & - & $\mathrm{w}$ & + & - & - \\
\hline Melezitose & - & - & + & - & - \\
\hline L-Rhamnose & - & + & + & + & - \\
\hline Trehalose & - & + & + & + & + \\
\hline \multicolumn{6}{|l|}{ Enzyme activities } \\
\hline$\alpha$-Arabinosidase & + & - & + & + & + \\
\hline$\beta$-Glucosidase & - & + & + & - & - \\
\hline$\beta$-Glucuronidase & - & $-{ }^{\star}$ & - & + & + \\
\hline Glutamic acid decarboxylase & - & - & + & + & + \\
\hline $\begin{array}{l}\text { Glutamyl glutamic acid } \\
\text { arylamidase }\end{array}$ & - & + & + & + & + \\
\hline Glycine arylamidase & - & + & + & + & + \\
\hline Histidine arylamidase & - & + & + & + & + \\
\hline Phenylalanine arylamidase & - & + & + & + & + \\
\hline Pyroglutamic acid arylamidase & - & - & - & - & + \\
\hline Serine arylamidase & - & + & + & + & + \\
\hline Tyrosine arylamidase & - & + & + & + & + \\
\hline
\end{tabular}

${ }^{\star}$ Reported as positive by Song et al. (2005) using Rosco diagnostic tablets.

isolates were somewhat different from those of other Parabacteroides species (Sakamoto \& Benno, 2006; Sakamoto et al., 2007). For P. goldsteinii JCM $13446^{\mathrm{T}}$, the major menaquinones are MK-9 (24\%) and MK-10 (67\%) and the minor menaquinones are MK-7 $(<1 \%)$, MK-8 $(3 \%)$ and MK-11 (4\%). The DNA G $+\mathrm{C}$ contents of strains MS- $1^{\mathrm{T}}$, MS-2 and MS-3 were $44.6,45.2$ and $42.3 \mathrm{~mol} \%$, respectively. These values were slightly lower than those recorded for other Parabacteroides species (46.5-47.6 mol\%) (Sakamoto et al., 2007).

Approximately 1500 bases of the 16S rRNA gene sequence were determined for the isolates. For the phylogenetic analysis, $1340 \mathrm{bp}$ (positions 61-1375; Escherichia coli numbering system) from each strain were used. $16 \mathrm{~S}$ rRNA gene sequence analysis showed that strain MS- $1^{\mathrm{T}}$ was a member of the genus Parabacteroides (Fig. 1) and was closely related to P. goldsteinii JCM $13446^{\mathrm{T}}$, with $95.9 \%$ $16 \mathrm{~S}$ rRNA gene sequence similarity. According to Stackebrandt \& Goebel (1994), strains showing 16S rRNA gene sequence similarity less than $97 \%$ will not show DNA-DNA reassociation values greater than $60 \%$ and will 
Table 2. Cellular fatty acid compositions of Parabacteroides gordonii sp. nov. and closely related species

Taxa: 1, Parabacteroides gordonii sp. nov. $(n=3) ; 2$, P. distasonis $(n=6) ; 3$, P. goldsteinii JCM $13446^{\mathrm{T}}$; 4, P. johnsonii JCM $13406^{\mathrm{T}}$; 5, P. merdae $(n=2)$. Data for reference taxa were taken from Sakamoto \& Benno (2006) and Sakamoto et al. (2007). Values are percentages of total fatty acids. ECL, Equivalent chain-length; ALDE, aldehyde; DMA, dimethylacetal; tr, trace amount $(<1 \%) ;-$, not detected/not reported.

\begin{tabular}{|c|c|c|c|c|c|}
\hline Fatty acid & 1 & 2 & 3 & 4 & 5 \\
\hline \multicolumn{6}{|l|}{ Saturated straight-chain } \\
\hline $12: 0$ & $\operatorname{tr}$ & - & - & - & - \\
\hline $14: 0$ & $1.3 \pm 0.1$ & $1.3 \pm 0.1$ & 1.1 & 1.1 & $1.4 \pm 0.1$ \\
\hline $15: 0$ & $1.8 \pm 0.5$ & $2.4 \pm 0.4$ & 2.0 & 5.5 & $1.4 \pm 0.1$ \\
\hline $16: 0$ & $4.8 \pm 0.2$ & $5.3 \pm 1.3$ & 7.2 & 5.4 & $5.9 \pm 1.6$ \\
\hline $17: 0$ & - & - & - & $\operatorname{tr}$ & - \\
\hline $18: 0$ & $\operatorname{tr}$ & $1.1 \pm 0.1$ & 1.7 & 1.1 & $1.2 \pm 0.2$ \\
\hline \multicolumn{6}{|c|}{ Unsaturated straight-chain } \\
\hline $14: 1 \omega 5 c$ & - & $\operatorname{tr}$ & - & $\operatorname{tr}$ & $\operatorname{tr}$ \\
\hline $16: 1 \omega 7 c$ & $1.5 \pm 0.3$ & $1.6 \pm 0.1$ & 1.9 & 1.0 & $1.6 \pm 0.1$ \\
\hline $16: 1 \omega 7 c$ DMA & $\operatorname{tr}$ & - & - & - & - \\
\hline $17: 1 \omega 8 c$ & - & $\operatorname{tr}$ & $\operatorname{tr}$ & - & $\operatorname{tr}$ \\
\hline $18: 2 \omega 6,9 c$ & $1.2 \pm 0.1$ & $1.3 \pm 0.1$ & 2.2 & 2.4 & $1.3 \pm 0.4$ \\
\hline $18: 1 \omega 9 c$ & $11.1 \pm 1.9$ & $14.8 \pm 1.2$ & 11.7 & 9.0 & $14.1 \pm 0.6$ \\
\hline \multicolumn{6}{|l|}{ Hydroxy } \\
\hline iso-15:0 $3-\mathrm{OH}$ & - & $\operatorname{tr}$ & - & $\operatorname{tr}$ & $\operatorname{tr}$ \\
\hline $15: 03-\mathrm{OH}$ & - & $\operatorname{tr}$ & - & $\operatorname{tr}$ & - \\
\hline iso-16:0 $3-\mathrm{OH}$ & - & $\operatorname{tr}$ & - & - & - \\
\hline $16: 03-\mathrm{OH}$ & $1.1 \pm 0.1$ & $4.9 \pm 0.6$ & 3.6 & 3.0 & $5.7 \pm 0.1$ \\
\hline iso- $17: 03-\mathrm{OH}$ & $3.8 \pm 1.6$ & $24.7 \pm 1.2$ & 26.3 & 21.3 & $26.0 \pm 0.1$ \\
\hline anteiso-17:0 $3-\mathrm{OH}$ & $1.7 \pm 0.6$ & $3.4 \pm 0.4$ & 7.9 & 3.1 & $4.2 \pm 1.1$ \\
\hline $17: 03-\mathrm{OH}$ & - & $1.2 \pm 0.2$ & 1.2 & 2.0 & 1.2 \\
\hline \multicolumn{6}{|l|}{ Aldehyde } \\
\hline $16: 0 \mathrm{ALDE}$ & 1.1 & - & - & - & - \\
\hline \multicolumn{6}{|c|}{ Saturated branched-chain } \\
\hline iso- $13: 0$ & $\operatorname{tr}$ & $\operatorname{tr}$ & - & $\operatorname{tr}$ & - \\
\hline iso- $14: 0$ & - & $\operatorname{tr}$ & - & $\operatorname{tr}$ & - \\
\hline iso- $15: 0$ & $7.1 \pm 0.4$ & $7.2 \pm 0.5$ & 4.3 & 8.1 & $8.0 \pm 0.3$ \\
\hline anteiso-15:0 & $44.8 \pm 2.7$ & $28.0 \pm 1.8$ & 26.5 & 32.2 & $25.3 \pm 0.3$ \\
\hline anteiso-17: 0 & $\operatorname{tr}$ & $\operatorname{tr}$ & $\operatorname{tr}$ & $\operatorname{tr}$ & $\operatorname{tr}$ \\
\hline \multicolumn{6}{|l|}{ Summed features ${ }^{*}$} \\
\hline 1 & $3.1 \pm 0.6$ & - & - & - & - \\
\hline 3 & $12.2 \pm 1.3$ & $\operatorname{tr}$ & - & 1.4 & $\operatorname{tr}$ \\
\hline 9 & $1.2 \pm 0.1$ & - & - & - & - \\
\hline 10 & 1.5 & $1.5 \pm 0.2$ & 1.6 & $\operatorname{tr}$ & $1.7 \pm 0.1$ \\
\hline 12 & - & $\operatorname{tr}$ & - & $\operatorname{tr}$ & $\operatorname{tr}$ \\
\hline
\end{tabular}

${ }^{*}$ Summed features represent groups of two or three fatty acids that cannot be separated by the Microbial Identification System. Summed feature 1 consisted of $13: 1 \omega 1 \mathrm{c}$ and/or 14:0 ALDE. Summed feature 3 consisted of ECL 13.570 and/or iso$15: 0$ ALDE. Summed feature 9 consisted of iso-16:0 3-OH and/or ECL 17.157. Summed feature 10 consisted of one or more

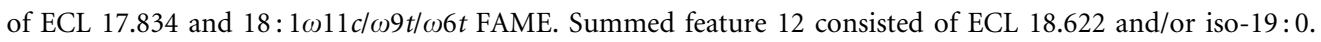

thus represent different species. The levels of sequence similarity among the three strains were $99.7-100 \%$.

Based on the phenotypic and biochemical characteristics and the 16S rRNA gene sequence analysis, we propose that these three strains represent a novel Parabacteroides species, Parabacteroides gordonii sp. nov. Parabacteroides species have been isolated from human blood cultures as a small population (2\%) (Simmon et al., 2008). The patient from whom Parabacteroides gordonii sp. nov. was isolated died approximately 3 months after admission. It is not known whether infection with this species had a role in the death of the patient.

Description of Parabacteroides gordonii sp. nov.

Parabacteroides gordonii (gor.do'ni.i. N.L. masc. gen. n. gordonii of Gordon, named after the American biologist 


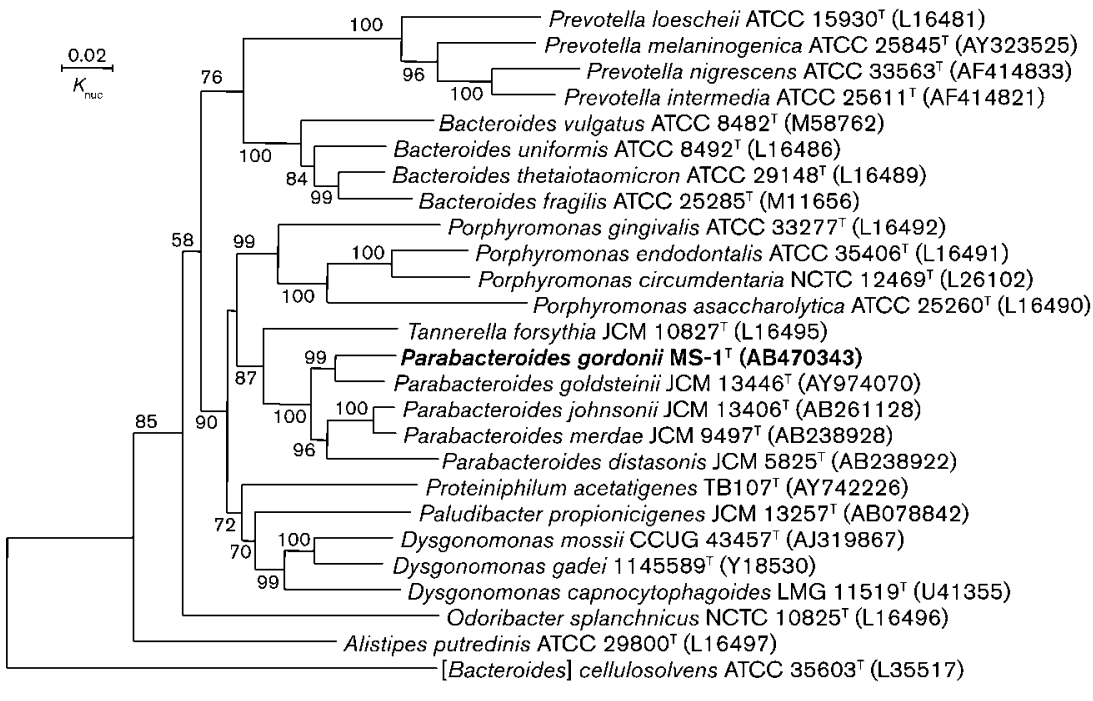

Fig. 1. Phylogenetic tree showing the relationship between Parabacteroides gordonii sp. nov. MS $-1^{\top}$ and related species, based on $16 \mathrm{~S}$ rRNA gene sequences and constructed with the neighbour-joining method. Percentages at nodes are levels of bootstrap support based on 1000 replicates. Bar, 0.02 substitutions per nucleotide position.
Jeffrey I. Gordon, in recognition of his many contributions to intestinal microbiology).

Cells are obligately anaerobic, non-spore-forming, nonmotile, Gram-negative rods $(0.8 \times 1.7-2.5 \mu \mathrm{m})$. Colonies on EG agar after $48 \mathrm{~h}$ of incubation at $37{ }^{\circ} \mathrm{C}$ under anaerobic conditions are $1-2 \mathrm{~mm}$ in diameter, grey to off-white-grey, circular, entire, slightly convex and smooth. Indole and urease are not produced. Catalase is variable (activity is not detected in the API 20A test but is detected on EG agar). Aesculin is not hydrolysed. Gelatin is not digested. Growth occurs on medium containing $20 \%$ bile. Acid is produced from L-arabinose, glucose, lactose, maltose, D-mannose, raffinose, sucrose and D-xylose, but not from cellobiose, glycerol, D-mannitol, melezitose, L-rhamnose, salicin, Dsorbitol or trehalose. Positive reactions are obtained using Rapid ID 32A for $\alpha$ - and $\beta$-galactosidase, $\alpha$-glucosidase, $\alpha$ arabinosidase, $N$-acetyl- $\beta$-glucosaminidase, alkaline phosphatase, arginine arylamidase, leucyl glycine arylamidase, leucine arylamidase and alanine arylamidase. Mannose and raffinose are fermented. All of the other tests that were performed in this study (urease, arginine dihydrolase, 6phospho- $\beta$-galactosidase, $\beta$-glucosidase, $\beta$-glucuronidase, glutamic acid decarboxylase, $\alpha$-fucosidase, nitrate reduction, indole production, proline arylamidase, phenylalanine arylamidase, pyroglutamic acid arylamidase, tyrosine arylamidase, glycine arylamidase, histidine arylamidase, glutamyl glutamic acid arylamidase and serine arylamidase) gave negative results. The major end product in peptone-yeast extract-glucose broth $(1 \%, \mathrm{w} / \mathrm{v}$, of each) is acetic acid; a small amount of succinic acid is also produced. The major cellular fatty acid is anteiso-15:0. The predominant respiratory quinone is menaquinone $\mathrm{MK}-10$. The DNA $\mathrm{G}+\mathrm{C}$ content of the type strain is $44.6 \mathrm{~mol} \%$.

The type strain is MS- $1^{\mathrm{T}}\left(=\mathrm{JCM} 15724^{\mathrm{T}}=\mathrm{CCUG} 57478^{\mathrm{T}}\right)$, isolated from human blood cultures. Two additional strains from the same source, MS-2 (=JCM 15725) and MS-3 (=JCM 15726), are included in this species.

\section{Acknowledgements}

We thank Dr M. A. Bakir for help with the 16S rRNA gene sequence analysis.

\section{References}

Eggerth, A. H. \& Gagnon, B. H. (1933). The bacteroides of human feces. J Bacteriol 25, 389-413.

Felsenstein, J. (1985). Confidence limits of phylogenies: an approach using the bootstrap. Evolution 39, 783-791.

Holdeman, L. V., Cato, E. P. \& Moore, W. E. C. (1977). Anaerobe Laboratory Manual, 4th edn. Blacksburg, VA: Virginia Polytechnic Institute and State University.

Johnson, J. L., Moore, W. E. C. \& Moore, L. V. H. (1986). Bacteroides caccae sp. nov., Bacteroides merdae sp. nov., and Bacteroides stercoris sp. nov. isolated from human feces. Int J Syst Bacteriol 36, 499-501.

Kimura, M. (1980). A simple method for estimating evolutionary rates of base substitutions through comparative studies of nucleotide sequences. J Mol Evol 16, 111-120.

Komagata, K. \& Suzuki, K. (1987). Lipid and cell-wall analysis in bacterial systematics. Methods Microbiol 19, 161-207.

Kuykendall, L. D., Roy, M. A., O'Neill, J. J. \& Devine, T. E. (1988). Fatty acids, antibiotic resistance, and deoxyribonucleic acid homology groups of Bradyrhizobium japonicum. Int J Syst Bacteriol 38, 358-361.

Larkin, M. A., Blackshields, G., Brown, N. P., Chenna, R., McGettigan, P. A., McWilliam, H., Valentin, F., Wallace, I. M., Wilm, A. \& other authors (2007). CLUSTAL $\mathrm{W}$ and CLUSTAL X version 2.0. Bioinformatics 23, 2947-2948.

Marmur, J. (1961). A procedure for the isolation of deoxyribonucleic acid from microorganisms. J Mol Biol 3, 208-218.

Miller, L. T. (1982). Single derivatization method for routine analysis of bacterial whole-cell fatty acid methyl esters, including hydroxy acids. J Clin Microbiol 16, 584-586.

Saito, H. \& Miura, K. (1963). Preparation of transforming deoxyribonucleic acid by phenol treatment. Biochim Biophys Acta 72, 619-629.

Saitou, N. \& Nei, M. (1987). The neighbor-joining method: a new method for reconstructing phylogenetic trees. Mol Biol Evol 4, 406425. 
Sakamoto, M. \& Benno, Y. (2006). Reclassification of Bacteroides distasonis, Bacteroides goldsteinii and Bacteroides merdae as Parabacteroides distasonis gen. nov., comb. nov., Parabacteroides goldsteinii comb. nov. and Parabacteroides merdae comb. nov. Int J Syst Evol Microbiol 56, 1599-1605.

Sakamoto, M., Suzuki, M., Umeda, M., Ishikawa, I. \& Benno, Y. (2002). Reclassification of Bacteroides forsythus (Tanner et al. 1986) as Tannerella forsythensis corrig., gen. nov., comb. nov. Int J Syst Evol Microbiol 52, 841-849.

Sakamoto, M., Huang, Y., Umeda, M., Ishikawa, I. \& Benno, Y. (2005). Prevotella multiformis sp. nov., isolated from human subgingival plaque. Int J Syst Evol Microbiol 55, 815-819.

Sakamoto, M., Kitahara, M. \& Benno, Y. (2007). Parabacteroides johnsonii sp. nov., isolated from human faeces. Int $J$ Syst Evol Microbiol 57, 293-296.
Shah, H. N. (1992). The genus Bacteroides and related taxa. In The Prokaryotes, 2nd edn, vol. 4, pp. 3593-3607. Edited by A. Balows, H. G. Trüper, M. Dworkin, W. Harder \& K. H. Schleifer. New York: Springer.

Simmon, K. E., Mirrett, S., Reller, L. B. \& Petti, C. A. (2008). Genotypic diversity of anaerobic isolates from bloodstream infections. $J$ Clin Microbiol 46, 1596-1601.

Song, Y., Liu, C., Lee, J., Bolanos, M., Vaisanen, M. L. \& Finegold, S. M. (2005). "Bacteroides goldsteinii sp. nov." isolated from clinical specimens of human intestinal origin. J Clin Microbiol 43, 4522-4527.

Stackebrandt, E. \& Goebel, B. M. (1994). Taxonomic note: a place for DNA-DNA reassociation and $16 \mathrm{~S}$ rRNA sequence analysis in the present species definition in bacteriology. Int J Syst Bacteriol 44, 846-849.

Tamaoka, J. \& Komagata, K. (1984). Determination of DNA base composition by reversed-phase high-performance liquid chromatography. FEMS Microbiol Lett 25, 125-128. 